\title{
Aplicação de Bucha Vegetal (Luffa Cylindrica) como Suporte para Produção de Xarope de Açúcar Invertido
}

\author{
Application of Loofa Sponge (Luffa cylindrica) as Carrier for \\ Invertase Immobilization for Invert Sugar Syrup Production
}

\author{
Evandro Cesar Poças ${ }^{1}$.; João Batista Buzato²; Maria Antonia Pedrine Colabone \\ Celligoi ${ }^{3}$; Doumit Camilios Neto ${ }^{4}$
}

\section{Resumo}

No presente trabalho, procedeu-se à imobilização de invertase em bucha vegetal (Luffa cylindrica) para produção de xarope de açúcar invertido. A imobilização consistiu de tratamento da bucha com $\mathrm{NaIO}_{4}$ seguido do uso de composto diamino, glutaraldeído e posterior imobilização da enzima. Os melhores resultados foram: atividade de invertase imobilizada: 4,510 (mmols/g de suporte $\mathrm{x}$ min $\mathrm{x}$ $\mathrm{mL}$ ); rendimento de imobilização: $0,428 \%$, atividade recuperada: $1,5 \%$ e extensão de hidrólise da sacarose de $2,6 \times 10^{-3} \% \cdot \mathrm{h}^{-1}$.

Palavras-chave: Imobilização. Invertase. Luffa Cylindrica.

\begin{abstract}
Invertase immobilization in loofa sponge (Luffa cylindrica) for invert sugar syrup production has been carried out. Loofa sponge was treated with $\mathrm{NaIO}_{4}$ followed by the use of diamine compound, glutaraldehyde and enzyme immobilization. The best results obtained were: invertase immobilized activity: 4.510 (mmols/g matrix x min $\mathrm{xL}$ ); enzyme coupling efficiency: $0.428 \%$, recovered activity: $1.5 \%$ and the extent of hydrolysis was of $2.6 \times 10^{-3} \% \cdot \mathrm{h}^{-1}$.
\end{abstract}

Key words: Immobilization. Invertase. Luffa Cylindrica.

${ }^{1}$ Graduando em química - Universidade Estadual de Londrina

${ }^{2}$ Docente do Dep. Bioquímica e Biotecnologia - Universidade Estadual de Londrina. - Email: buzato@uel.br

${ }^{3}$ Docente do Dep. Bioquímica e Biotecnologia - Universidade Estadual de Londrina

${ }^{4}$ Mestrando em Biotecnologia - Universidade Estadual de Londrina 


\section{Introdução}

Nos últimos anos, o estudo da imobilização de enzimas tem enfocado diversos aspectos, tanto nos suportes usados como o fundamento do método da imobilização. Entretanto muito dos materiais utilizados em imobilização são sintéticos e nãobiodegradáveis, o que causa problemas no meio ambiente após sua utilização. Outros, por sua vez, são tóxicos ou mesmo conferindo ao produto propriedades indesejáveis tais como cor, sabor e aroma, o que os tornam inapropriados para imobilização principalmente na indústria de alimentos (GEMEINER; STEFUCA; BALES, 1993; OGBONNA; TOMIYAMA; TANAKA, 1996). Existe, assim, a necessidade da busca de materiais alternativos para serem usados como suporte. As qualidades esperadas dos materiais alternativos é que sejam renováveis, biodegradáveis, de baixo custo, bem como de fácil disponibilidade particularmente em países em desenvolvimento (OGBONNA; TOMIYAMA; TANAKA, 1996). Tem sido relatado o uso de diversos compostos de natureza celulósica que apresentam essas características. Entre eles citam-se o bagaço de cana, pedaços de madeira, póde-serra e casca de arroz (CHEUNG et al., 1986; CHOU; JASOVISKY, 1993).

A bucha vegetal (Luffa cylindrica) é de crescimento fácil em nosso país. É leve, cilíndrica e apresenta naturalmente uma arquitetura entrelaçada e altamente porosa. Essas características conferem a esse material um potencial de uso como suporte em imobilização (OGBONNA; TOMIYAMA; TANAKA, 1996).

O Paraná é o segundo maior produtor de açúcar e álcool e na região de Londrina estão localizadas diversas usinas de açúcar e álcool.

Sendo assim, essa grande produção de cana-deaçúcar representa um desafio para utilização do açúcar, caldo e melaço de cana-de-açúcar como matéria prima na produção de compostos de valor agregado mais elevado que o açúcar e o etanol.
O termo xarope de açúcar invertido descreve uma mistura de açúcares em solução, principalmente glicose, frutose e sacarose obtida através da reação de hidrólise da sacarose, também denominada inversão (CHOU; JASOVISKY, 1993). Para a produção do açúcar invertido, dois métodos podem ser usados: a hidrólise enzimática, catalisada pela enzima invertase e a hidrólise ácida, catalisada por um ácido. Entretanto, na hidrólise ácida ocorre a formação de produtos secundários, os quais devem ser removidos. Embora a invertase seja uma enzima de custo relativamente baixo, sua utilização na forma livre em sistema de batelada reduz a eficiência do processo. Sendo assim, o desenvolvimento de uma tecnologia de invertase imobilizada oferece uma alternativa de reutilização da enzima e para baratear o processo (GEMEINER; STEFUCA; BALES, 1993). Dessa maneira, o desenvolvimento de uma tecnologia de invertase imobilizada oferece uma alternativa para um sistema contínuo de hidrólise da sacarose no qual possibilita a reutilização da enzima.

\section{Materiais e Métodos}

Aminoácido: Solução composta de $0,1 \mathrm{~g} / \mathrm{mL}$ de lisina, asparagina, histidina, arginina, glutamina e ornitina dissolvidos em tampão citrato-fosfato $(0,1 \mathrm{M})$.

Solução bloqueadora: A solução bloqueadora foi preparada numa concentração de $2,5 \mathrm{mg}$ de aminoácidos (triptofano, leucina, glicina, arginina e ác. aspártico) / $\mathrm{mL}$ dissolvidos em tampão citratofosfato $(0,1 \mathrm{M})$.

Invertase: A enzima invertase $\left({ }^{2}\right.$-frutofuranosidase; E.C. 3.2.1.26) de S. cerevisiae, gentilmente cedida pela Novo Nordisk Bioindustrial Ltda, foi utilizada na concentração de $220 \mathrm{mg} \%$ de proteínas, em tampão citrato-fosfato $(0,1 \mathrm{M})$.

Polietilenoimina (PEI): Solução de Polietilenoimina $1 \%(\mathrm{v} / \mathrm{v})$ tamponada em citrato-fosfato $\mathrm{pH} 7,0$.

Atividade enzimática: Foi determinada na solução de enzima livre inicial, na solução de pósimobilização, na água de lavagem com tampão 
citrato-fosfato e na enzima imobilizada. Transferiuse $1 \mathrm{~mL}$ de solução de invertase ou três pedaços de bucha com a invertase imobilizada para $25 \mathrm{~mL}$ de sacarose $1 \%(\mathrm{P} / \mathrm{V})$ em tampão citrato-fosfato, temperatura de $37^{\circ} \mathrm{C}$. Decorrido o tempo de hidrólise (1 a 5 minutos), o açúcar redutor formado foi determinado pelo método de Somogy e Nelson (NELSON, 1944). As unidades para atividade de invertase livre e imobilizada são respectivamente $\mu \mathrm{mols} / \mathrm{mL} \mathrm{x}$ min. e mmols/g de suporte $\mathrm{x} \min \mathrm{x} \mathrm{mL}$. Para calcular a atividade enzimática de invertase livre, pós-imobilização e da água de lavagem com tampão citrato-fosfato, utilizou-se a seguinte fórmula: Absorvância x (1/ inclinação da curva de calibração) x (1/ volume Enzima) x (1/ volume hidrolisado) x (1/ tempo de reação) $\mathrm{x}$ diluição. A unidade desta fórmula é dada como: $\mu$ mols $/ \mathrm{mL} \mathrm{x}$ min. Para calcular a atividade enzimática de invertase imobilizada utilizou-se a seguinte fórmula: Absorvância x (1/inclinação da curva de calibração) x (1/g de suporte) x (1/volume hidrolisado) x (1/ tempo de reação) $\mathrm{x}$ diluição. A unidade desta fórmula é dada como: $\mu \mathrm{mols} / \mathrm{g}$ de suporte $\mathrm{x}$ min.

Rendimento de imobilização: para calcular o rendimento da imobilização (\%), utilizou-se a seguinte fórmula: [Atividade enzimática da invertase imobilizada / Atividade enzimática livre x volume enzimático utilizado] x 100.

Atividade recuperada: para calcular a atividade recuperada (\%) utilizou-se a seguinte fórmula: [Atividade enzimática imobilizada / absorbância enzimática livre $\mathrm{x}$ ( $1 / \mathrm{g}$ de suporte) $\mathrm{x}$ fator de diluição x (1/inclinação) x (1/tempo de reação) ] x 100 .

Extensão de hidrólise: para calcular a extensão de hidrólise (conversão de substrato em produto) utilizou-se a seguinte formula: [ (quantidade de glicose no hidrolisado) / (quantidade teórica de glicose no substrato $\mathrm{x}$ tempo) ] x 100\%.

Procedimento padrão de Imobilização: Utilizaram-se três pedaços de bucha vegetal de $2 \mathrm{~cm}^{2}$ $(0,08 \mathrm{~g}$ cada pedaço $)$ tratados com $150 \mathrm{~mL}$ de $\mathrm{NaIO}_{4}$ $(20 \mathrm{mM})$ tamponado, por 30 minutos na temperatura de $4^{\circ} \mathrm{C}$ com agitação. Decantou-se o sobrenadante e lavaram-se as buchas com água destilada três vezes. A seguir, os pedaços de bucha foram embebidos em $150 \mathrm{~mL}$ da solução de aminoácidos por 24 horas na temperatura ambiente com agitação. Decantou-se o sobrenadante e lavaram-se as buchas com água destilada três vezes. A seguir, os pedaços de bucha foram embebidos em $150 \mathrm{~mL}$ de glutaraldeído $(2,5 \%$ $\mathrm{V} / \mathrm{V})$ tamponado por 30 minutos na temperatura ambiente com agitação.

Decantou-se o sobrenadante e lavaram-se as buchas com água destilada três vezes. Em seguida, os pedaços de bucha foram embebidos em $150 \mathrm{~mL}$ da solução de invertase tamponado por 24 horas na temperatura de $4^{\circ} \mathrm{C}$ com agitação. Decantou-se e reservou-se o sobrenadante. Em seguida, os pedaços de bucha forem embebidos em $150 \mathrm{~mL}$ de tampão citrato-fosfato $(0,1 \mathrm{M})$ por alguns minutos. Decantouse e reservou-se o sobrenadante. A seguir, lavaramse os pedaços de bucha duas vezes com tampão citrato-fosfato. A seguir, os pedaços de bucha foram embebidos em solução bloqueadora por 2 horas na temperatura de $4^{\circ} \mathrm{C}$ com agitação. Decantou-se o sobrenadante e lavaram-se as buchas com tampão citrato-fosfato três vezes. Em seguida, os pedaços de bucha foram embebidos em $150 \mathrm{~mL}$ de $\mathrm{NaBH}_{4}$ $(0,1 \mathrm{M})$ por 30 minutos na temperatura ambiente com agitação. Descartou-se o sobrenadante e lavou-se os pedaços de bucha três vezes com tampão citratofosfato. Em seguida, os pedaços de bucha foram lavados três vezes em $150 \mathrm{~mL}$ de $\mathrm{NaCl}(1,0 \mathrm{M})$ por alguns minutos na temperatura ambiente. A seguir, os pedaços foram embebidos em tampão até serem utilizados.

Seqüência dos procedimentos de imobilização:
A) Bucha $\rightarrow \mathrm{NaIO}_{4} \rightarrow$ Aminoácidos $\rightarrow$ Glutaraldeído $\rightarrow$ Invertase $\rightarrow$ Solução bloqueadora $\rightarrow \mathrm{NaBH}_{4} \rightarrow \mathrm{NaCl}$
B)Bucha $\rightarrow \quad \mathrm{NaIO}_{4} \rightarrow \quad$ Aminoácidos $\rightarrow \quad \mathrm{NaBH}_{4} \rightarrow$ Glutaraldeído $\rightarrow \mathrm{NaBH}_{4} \rightarrow$ Invertase $\rightarrow$ Solução Bloqueadora $\rightarrow \mathrm{NaBH}_{4} \rightarrow \mathrm{NaCl}$

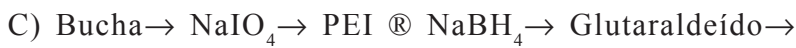 $\mathrm{NaBH}_{4} \rightarrow$ Invertase $\rightarrow$ Solução bloqueadora $\rightarrow \mathrm{NaBH}_{4} \rightarrow \mathrm{NaCl}$ 
D) Bucha $\rightarrow \mathrm{NaIO}_{4} \rightarrow$ Aminoácidos $\rightarrow \mathrm{NaBH}_{4} \rightarrow$ Glutaraldeído $\rightarrow \mathrm{NaBH}_{4} \rightarrow$ PEI $\rightarrow \mathrm{NaBH}_{4} \rightarrow$ Glutaraldeído

$\rightarrow \mathrm{NaBH}_{4} \rightarrow$ Invertase $\rightarrow$ Solução bloqueadora $\rightarrow \mathrm{NaBH}_{4}$ $\rightarrow \mathrm{NaCl}$

Os procedimentos A e B foram conduzidos utilizando tampão citrato-fosfato $\mathrm{pH} 5$ e 7, enquanto os procedimentos $\mathrm{C}$ e $\mathrm{D}$ foram conduzidos somente em $\mathrm{pH} 7$.

Esses tampões também foram usados no procedimento $\mathrm{B}$ além de ter sido usado 3 vezes o $\mathrm{NaBH}_{4}$ (após o uso de aminoácido, glutaraldeído e enzima). $\mathrm{O}$ procedimento $\mathrm{C}$ usou PEI no lugar de aminoácido e 3 vezes o $\mathrm{NaBH}_{4}$. O procedimento D usou aminoácido, PEI e 5 vezes o $\mathrm{NaBH}_{4}$ (após aminoácido, glutaraldeído, PEI, glutaraldeído e enzima).

\section{Resultados e Discussão}

Considerando-se a potencialidade da aplicação de enzimas imobilizadas particularmente na indústria de alimentos e a pouca exploração da utilização de materiais de baixo custo e isentos de toxidez, como suporte na imobilização, estamos propondo o uso da bucha vegetal. Em teoria, o tratamento da bucha vegetal com periodato leva a oxidação dos carbonos adjacentes nas moléculas de glicose da celulose, que resulta na formação de grupos aldeídos. $\mathrm{O}$ uso de ativação de polissacarídios por meio do periodato não é novo e foi inicialmente usado na ativação de sephadex em preparações imunoadsorventes (WILSON; NAKANE, 1976). Em seguida, o dialdeído reage com um composto diamino e cria-se assim, a Base de Schiff. Em seguida, é conduzido o tratamento com glutaraldeído onde ocorre a formação da segunda Base de Schiff, entre o grupamento amino livre do composto diamino e o glutaraldeído. $\mathrm{Na}$ última etapa, a bucha vegetal ativada é embebida na solução enzimática e uma terceira Base de Schiff é formada, entre o grupamento aldeído livre do glutaraldeído com algum grupamento amino livre da enzima. As Bases de Schiff criadas são estabilizadas pelo tratamento com $\mathrm{NaBH}_{4}$. As Bases de Schiff são relativamente instáveis, especialmente em valores de pH baixos, mas podem ser estabilizadas pela redução com $\mathrm{NaBH}_{4}($ KENNEDY, 1990).

A invertase imobilizada na bucha vegetal foi usada para hidrolisar a sacarose e os resultados obtidos, nas diferentes seqüências (A, B, C e D) do procedimento de imobilização, estão apresentados na tabela 1 .

Tabela 1. Valores de atividade de invertase livre e imobilizada em Luffa cylindrica

\begin{tabular}{|c|c|c|c|c|c|}
\hline & $\begin{array}{c}\text { Tratamentos com } \\
\mathrm{NaBH}_{4} \\
\text { tamponado }\end{array}$ & $\begin{array}{l}\text { Atividade } \\
\text { Livre }\end{array}$ & $\begin{array}{c}\text { Atividade } \\
\text { Imobilizada }\end{array}$ & $\begin{array}{l}\text { Rendimento de } \\
\text { imobilização }\end{array}$ & $\begin{array}{l}\text { Atividade } \\
\text { recuperada }\end{array}$ \\
\hline & $\begin{array}{ll}* & \mathrm{pH}\end{array}$ & & & & \\
\hline $\mathrm{A}$ & 5,0 & 12,182 & 0,943 & 0,052 & 0,184 \\
\hline & 7,0 & 6,743 & 2,168 & 0,219 & 0,772 \\
\hline B & 5,0 & 10,97 & 0,818 & 0,050 & 0,179 \\
\hline & 7,0 & 7,078 & 4,044 & 0,383 & 1,371 \\
\hline $\mathrm{C}$ & 7,0 & 7,139 & 2,912 & 0,274 & 0,979 \\
\hline $\mathrm{D}$ & 7,0 & 7,075 & 4,510 & 0,428 & 1,530 \\
\hline
\end{tabular}

*Número de vezes 
A celulose é disponível em diversas formas físicas e em processos industriais é possível o uso de celulose menos pura: corda, polpa, bagaço, tecido ou papel. Em imobilização da invertase, o material celulósico mais rústico usado como suporte, foi o pulverizado de sabugo de milho em processo de fluxo contínuo de inversão da sacarose (MONSAN; COMBES, 1984).

No presente trabalho, a metodologia foi testada com variações. Os resultados do Procedimento A, por meio do qual foram testados valores de $\mathrm{pHs} 5,0$ e 7,0 mostraram que a hidrólise da sacarose foi maior em $\mathrm{pH}$ 7,0. Broggi et al. (2002) imobilizaram invertase utilizando a presente metodologia, contudo o tampão usado foi acetato e somente em pH 5. Esses autores obtiveram valores inferiores: 0,18 (mmols/g de suporte $\mathrm{x} \min \mathrm{x} \mathrm{mL}$ ) de atividade enzimática imobilizada embora o rendimento de imobilização foi maior: 3,64(\%). Os resultados do presente trabalho demonstram que a utilização do tampão citrato-fosfato desfavoreceu o rendimento de imobilização, porém a quantidade de enzima imobilizada apresentou uma maior atividade enzimática. Poças, Buzato e Celligol (2004) utilizaram albumina bovina no lugar de aminoácidos e em pHs 5 e 7 . O valor obtido foi de 3,63 (mmols/g de suporte $\mathrm{x}$ min $\mathrm{x} \mathrm{mL}$ ) de atividade imobilizada e não houve preferência em relação aos valores de $\mathrm{pH}$ testados e tratamentos com $\mathrm{NaBH}_{4}$. No procedimento $\mathrm{B}$, os valores foram melhorados com o aumento do número de uso de $\mathrm{NaBH}_{4}$ para 3 vezes. No tratamento $\mathrm{C}$, o PEI foi utilizado no lugar de aminoácido e o resultado foi inferior ao tratamento B. O procedimento D que usou a seqüência de tratamentos: aminoácido, glutaraldeído, PEI e glutaraldeído, obteve os maiores valores: 4,510 (mmols/g de suporte $\mathrm{x}$ min $\mathrm{x} \mathrm{mL}$ ) de atividade imobilizada; 0,428 (\%) de rendimento de imobilização; 1,53 (\%) de atividade recuperada e $2,6 \times 10^{-3} \% \cdot h^{-1}$ de extensão de hidrólise.

\section{Conclusão}

O uso de invertase imobilizada em bucha vegetal é promissor na obtenção de xarope de açúcar invertido e os melhores resultados foram obtidos quando o suporte é tratado, previamente à imobilização, na seguinte seqüência: aminoácido, glutaraldeído, PEI e glutaraldeído.

\section{Referências}

BROGGI, R. L.; BUZATO, J. B.; CELLIGOI, M. A. P. A. Nova metodologia de imobilização enzimática utilizando bucha vegetal (luffa cylindrica): aplicação na imobilização de invertase. In: SEMINÁRIO BRASILEIRO DE TECNOLOGIA ENZIMÁTICA, 5., 2002, Brasília. Anais... Brasília: UNB, 2002. p.106.

CHEUNG, I. H. S.; GISHEN, M.; GHOSH, P. E PAMMANT, N. B. Continuous ethanol-production in an immobilized whole cell fermenter using untreated sugarcane bagasse as carrier. Applied Microbiology and Biotechnology, Berlin, v.23, n.6, p.413-416, Mar. 1986.

CHOU, C. C.; JASOVISKY, G. A. Advantages of Ecosorb precoats in liquid sugar production. International Sugar Journal, Glamorgan, v.95, n.1138, p.425-430, 1993.

GEMEINER, P.; STEFUCA, V.; BALES, V. Biochemical engineering of biocatalystic immobilized on cellulosic materials. Enzyme and Microbial Technology, New York, v.15, p.551-556, 1993.

KENNEDY, J. F. Carbohydrate chemistry. Oxford: Clarendon Press, 1990.

MONSAN, P.; COMBES, D. Application of immobilized invertase to continuous hydrolysis of concentrated sucrose solutions. Biotechnology \& Bioengineering, New York, v.26, p.347-351, 1984.

NELSON, N. A. Photometric adaptation of the Somogyi method for determination of glucose. Analytical Biochemistry, New York, v.153, p.375-380, 1944.

OGBONNA, J. C.; TOMIYAMA, S.; TANAKA, H. Development of a method for immobilization of no flocculating cells in loofa (Luffa cylindrica) sponge. Process Biochemistry, London, v.31, n.8, p737-744, 1996.

POÇAS, E. C.; BUZATO, J. B.; CELLIGOI, M. A. P. C. Otimização na imobilização de invertase em luffa cylindrica para produção de xarope invertido. In: SEMINÁRIO BRASILEIRO DE TECNOLOGIA ENZIMÁTICA, 6., 2004, Rio de Janeiro. Anais... Rio de Janeiro: ABEQ, 2004. p. 49.

WILSON, M. B.; NAKANE, P. K. The covalent coupling of proteins to periodate-oxidized sephadex: a new approach to immunoadsorbent preparation. Journal of Immunological Methods, Amsterdam, v.12, n.1/2, p.171$181,1976$. 